\title{
Rural communities and transportation equity in California's San Joaquin Valley
}

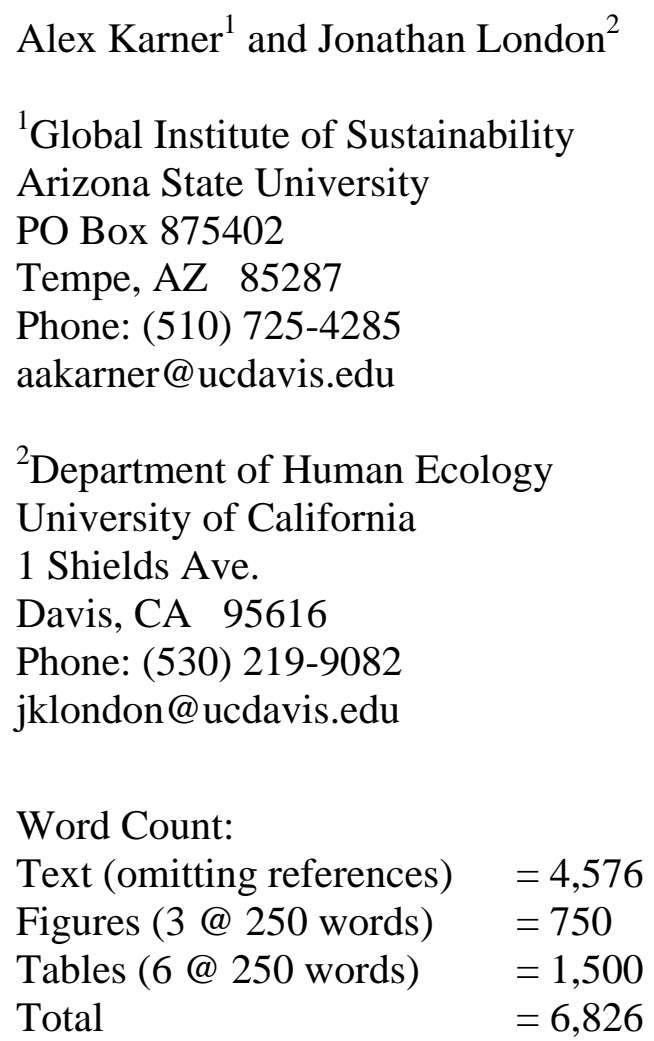

${ }^{1}$ Corresponding author

Paper published in the Transportation Research Record: Journal of the Transportation Research Board. Citation:

Karner, A. and J. London (2014). "Rural Communities and Transportation Equity in California's San Joaquin Valley." Transportation Research Record: Journal of the Transportation Research Board 2452: 90-97. 


\begin{abstract}
Smart growth policy and planning have tended to emphasize urban centers and regions, yet rural communities can also be important sites of innovation. Recent work has demonstrated their surprisingly high levels of current and potential non-motorized travel, and legislation in California mandates greenhouse gas emissions reductions across all of the state's metropolitan planning organization (MPO) regions, including the heavily rural San Joaquin Valley (SJV). Advocates for rural communities are finding common cause with more traditional environmental organizations around the vision of investing in and enhancing extant rural places as an alternative to leapfrog patterns of urban and suburban sprawl. Because of existing patterns of extreme disparity and legion under-served unincorporated communities, analyses that can help integrate social equity within regional planning are needed to serve and empower rural residents. This study presents the results of several new analyses of the social equity dimensions of regional transportation plans in the SJV. We employ activity-based travel model data to analyze equity, focusing particularly on eight "disadvantaged unincorporated communities" identified by community advocates as important demonstration sites. We show how improvements in traditional equity analysis can enhance their consideration in the planning process and compare results developed with innovative techniques to their traditional counterparts. Because of the small size of these communities, they would likely to be overlooked in typical regional equity analyses. The methods outlined here can make substantial contributions to reducing disparities in rural communities and offer lessons for MPOs serving rural areas across the country.
\end{abstract}




\subsection{INTRODUCTION}

Research, policy, and practice associated with smart growth in the United States has tended to focus on urban centers and regions as opposed to rural communities $(1,2)$. While an urban dimension of smart growth is necessary, it is not sufficient. Lower density settlement patterns result in relatively high vehicle-miles traveled (VMT) and associated greenhouse gas (GHG) and air pollution emissions. Recent California legislation such as the Global Warming Solutions Act (AB 32) and the Sustainable Communities and Climate Protection Act (SB 375) set targets for per capita GHG/VMT reductions for all regions, necessitating a rural smart growth approach to complement the dominant urban smart growth frameworks.

California's eight-county San Joaquin Valley (SJV) contains a mosaic of urban, suburban and rural communities, and represents both a challenge and an opportunity to develop innovative approaches to promote smart growth. Profound income and wealth disparities create a regional pattern of "poverty amidst prosperity" (3). The highest intensity of environmental hazards cluster around the places and populations with the least social, economic, and political resources to address them (4). While nominally represented by their host county governments, unincorporated communities struggle to exert a political voice and to fund and manage key infrastructure (5). Such communities suffer from their physical distance from county seats and the political marginalization that results from representing a rather small fraction of the electorate for county elected officials (6). These factors prevent many of their low-income residents, who are predominately people of color and first or second-generation immigrants, from accessing the economic, educational, and environmental resources needed to sustain a high quality of life (7).

In spite of these problems, rural communities can be sites of innovation in smart growth policy and planning (7). Recent work has demonstrated their surprisingly high levels of current and potential non-motorized travel (8). Advocates for rural communities are finding common cause with more traditional environmental organizations around the vision of investing in and enhancing existing rural places as an alternative to leapfrog patterns of urban and suburban sprawl. The former strategy simultaneously benefits extant rural communities and protects agriculture, air quality, natural resources, and wildlife habitat.

Analyses that can help integrate social equity within regional planning are needed to serve and empower rural residents. This study presents the methods and results of several new analyses of the social equity dimensions of regional transportation plans in California's SJV. We employ activity-based travel model data to analyze equity, focusing particularly on eight "disadvantaged unincorporated communities" (DUCs) identified by community advocates as important demonstration sites. We show how improvements in traditional equity analysis can enhance their consideration in the planning process and compare results developed with innovative techniques to their traditional counterparts. Because of the small size of these communities, they would likely to be overlooked in typical regional equity analyses. The methods outlined here can make substantial contributions to reducing disparities in rural communities and offer lessons for metropolitan planning organizations (MPOs) serving rural areas across the country.

\subsection{OVERVIEW OF EQUITY ANALYSIS PRACTICE}

The Fresno Council of Governments (FCOG) conducted the most analytically rigorous equity analysis in the SJV for the 2011 RTP cycle (9). The analysis (10) largely follows the traditional three-step approach described by Karner and Niemeier (11) which defines at least two 
population groups using geographic thresholds (one often labeled "communities of concern" or "environmental justice (EJ) zones" which are compared to the remainder of the region or the region as a whole), calculates transportation performance measures for both aggregations, and compares the results. FCOG defined communities of concern as traffic analysis zones (TAZs) with population proportions $60 \%$ higher than the county average proportion on one of four categories (low-income, people of color, seniors 65 and older, and disabled). Seven performance measures, including transportation accessibility and mobility, were calculated for communities of concern and compared to a regional average for 1998, 2030 build, and 2030 no build conditions.

The FCOG report concluded that "programmed transportation investments in Fresno County result in fair distribution of impacts and benefits ... when comparing environmental justice TAZs and non-environmental justice TAZs in Fresno County" (10, p. 26). However, the analysis contains several shortcomings that may undermine this conclusion's validity. The mobility and accessibility metrics are based upon theoretical trips and their travel times with destinations at major job centers (accessibility) and every TAZ in the region (mobility). Simply showing that a similar level of transit service is available in EJ zones and all other zones is not particularly informative. The average actual commute time by transit from EJ zones and all other zones to actual commute destinations would be a far more meaningful measure than that currently used.

The traditional approach likely obscures key dimensions of equity, but there are methodological choices that can increase the relevance of an analysis (12). Travel models are developed from observed travel behavior, calibrated to and validated against observed data, and so can be meaningfully said to reflect the tradeoffs that individuals and households make between travel time and cost, automobile ownership, and to some degree household and workplace location. Given their ubiquity, studying and disseminating improved methods for travel demand model-based equity analysis and visualization that investigate known sites of inequity, based on local knowledge and past research, can advance both the theory and practice of equity analysis.

\subsection{METHOD AND DATA}

We employed activity-based travel demand model data for 2008 from the San Joaquin Valley Interregional Travel Demand Model (SJVITM) (13). The SJVITM was created by the UC Davis Urban Land Use and Transportation Center (ULTRANS). This work employs results only from the base year to characterize existing patterns of transportation equity. The model takes a synthetic population of individuals and households through a series of short- and long-term decisions on travel and location, respectively. ULTRANS drew the synthetic population from the 2008 ACS Public Use Microdata Sample and calibrated the population to match zonal totals provided by MPOs for various travel-relevant demographics.

We combined the SJVITM outputs with data from the US Census to analyze patterns of transportation equity in the SJV. Data on the racial and ethnic composition of TAZs were developed using the 2010 US Census Summary File 1, and data on income were taken directly from the synthetic population. Poverty measures were calculated using 2008 Census poverty definitions at the synthetic household level (14). Transportation performance measures were calculated using both work and non-work trips. Skims for non-motorized travel times were calculated using data reported by Maizlish et al. (15) for bicycling and walking. Cost skims for automobile were similarly calculated, using the 2013 IRS standard mileage deduction converted 
to year 2000 dollars (\$0.43/mile) to maintain consistency with reported household income values.

We employed transportation performance metrics of particular relevance to equity stakeholders including: place-based cumulative opportunities accessibility to healthcare by automobile and transit, a composite accessibility measure that considers automobile sufficiency, commute properties (time, cost, distance), and commute costs as a proportion of household income. Equity in the use of non-motorized modes is also quantified. While traditional equity analyses typically only report results at a single, regional scale, we report results at multiple scales including region, county, DUC, threshold-based "community of concern," and for all households in poverty.

\subsection{Study area}

California Rural Legal Assistance (CRLA), a non-profit legal organization dedicated to improving rural community well-being, developed a community-based process to identify the eight study DUCs employed here. DUCs include West Fresno, Lanare, Riverdale, Laton, Arvin, Lamont, Greenfield, and Weedpatch (Figure 1). Six are Census-Designated Places (CDPs) located within county jurisdictions. Arvin is a city, which also has an associated CDP, while West Fresno is an area located in part within the City of Fresno and Fresno County. To report equity analysis results corresponding to the study area DUCs, TAZs were associated with CDP and ZCTA boundaries. TAZs that fell completely within the CDP boundaries were included. If a TAZ with a relatively high population appeared to fall mostly within the CDP boundaries, it was also included. In the smaller DUCs, at least a single TAZ contained the population center of the community, and this was taken as representative. The correspondence of TAZs to DUCs is summarized in Table 1. Clearly, some DUCs are better captured within the existing TAZ structure than others. Specifically, population totals for the DUCs in Kern County more closely match Census totals.

\subsection{RESULTS AND DISCUSSION}

\subsection{Study area demographics}

Demographics for each of the eight DUCs, Fresno and Kern counties, the eight-county SJV region, and California as a whole, taken from the 2010 Census and the American Community Survey 2007 - 2011 five year estimates are summarized in Table 2. Most of the DUCs identified by CRLA evidence substantial disadvantage, with each reported indicator under-performing both the host county and the state. Six identified DUCs have relatively high poverty and linguistic isolation and low per-capita income: Lanare, Riverdale, West Fresno, Arvin, Lamont, and Weedpatch. All eight study communities exceed the statewide and countywide proportions of people of color. Data on non-single occupancy vehicle (SOV) mode share are more limited due to the vagaries of the ACS data, but in DUCs with reliable estimates, commuting by SOV appears to be less common than would be expected based on the county or statewide values, highlighting a potential link between transport disadvantage and social disadvantage.

Two identified communities, Greenfield and Laton, generally over-perform county and state indicators. They are still of interest for two reasons. First, based on local accounts of Laton, the community is likely to evidence substantial disparity. A relatively affluent segment of the population is likely to be driving the overall mean indicators. Second, Greenfield is located within the South Kern Building Health Communities (BHC) site. BHC is a 10 year community 
development initiative, supported by The California Endowment, to improve conditions in 14 specific locations in California (16). Additionally, both Greenfield and Laton demonstrate that conditions within unincorporated areas are not uniformly negative. Including them in the analysis can provide an important point of comparison for DUCs and planning agencies.

\subsection{Accessibility}

Accessibility refers to the ease with which desired destinations can be reached with a given combination of transportation infrastructure, land uses, and travel mode. Many different measures of accessibility have been proposed and applied, and reviews of the accessibility literature are numerous (see, e.g., 17, 18, 19). Accessibility is an attractive concept in part because it can be improved via non-transportation interventions, including economic development and land use strategies to bring destinations closer to individuals and families. Efforts to promote these non-transportation strategies are inextricable from smart growth planning goals.

Limited accessibility in DUCs is of great concern. To identify existing patterns of accessibility, we employ the place-based cumulative opportunities accessibility index shown in Equation 1:

$$
A_{i m}=\sum_{j} x_{a j}, \text { where } t_{i j m} \leq T
$$

where $A_{i m}$ is the total number of jobs accessible from zone $i$ by mode $m$ within time threshold $T$, $x_{a j}$ is the number of jobs of type $a$ in zone $j$, and $t_{i j m}$ is the travel time from TAZ $i$ to TAZ $j$ by mode $m$.

Although integral measures of accessibility suffer from many shortcomings $(18,19)$, including not being linked to actual trips, they are appropriate to provide an initial indication of the accessibility afforded to a community as a whole. Additionally, the cumulative opportunities measure is easily interpretable and is likely to reflect the accessibility of the relatively small geographic zones studied here.

TAZ-to-TAZ skims from the AM peak period were taken for single occupancy vehicles and walk to transit from the SJVITM. Three measures of accessibility were calculated: drive alone, walk to transit, and a composite measure weighted by the proportion of automobile insufficient households in a geographic area, following an approach similar to that described by Golub et al. (20). Here, an automobile-sufficient household was defined as having number of vehicles equal to or greater than the number of licensed drivers. Weighting the accessibility metric in this way attempts to more closely match the experience of residents in the TAZs for which accessibility is calculated. Table 3 summarizes the cumulative opportunities accessibility indicators for 15, 30, and 45 minute travel time thresholds for the entire SJVITM region for four types of jobs included in the model and of particular relevance to DUC stakeholders. Detailed data on facility location were not available, so number of jobs was used as a proxy for the desirability of destinations.

Not surprisingly, given the rural nature of the SJV, there is very low transit accessibility overall; automobile accessibilities are generally two or three orders of magnitude greater than transit accessibilities. The regional rate of modeled automobile sufficient households is $83 \%$; household automobile sufficiency is clearly necessary to achieve access to the major jobs centers in the SJV. For this reason, the composite accessibility indicator closely resembles the values calculated for automobile accessibility. 
To obtain finer detail on the study DUCs, Table 4 summarizes the same accessibility metrics as above, but for the groups of TAZs associated with the identified DUC and Fresno and Kern Counties. These results are reported for access to healthcare jobs only (used as a proxy for access to healthcare). Prior work has associated rurality with increased travel distances, times, and decreased frequency of medical visits overall and to specialists relative to urban areas (21). Acury et al. (22) showed that licensed drivers and those with access to rides through their families made significantly more health-service related trips. These studies illustrate the importance of considering rural access to healthcare during the transportation planning process.

The results provide a stark indication of the difficulties faced by some DUCs and all transitdependent individuals in accessing healthcare. Only Greenfield and West Fresno exceed the regional average accessibility to health care jobs within 30 minutes. All of the other identified DUCs are below average. Lanare, Riverdale, Laton, and Arvin have access to an order of magnitude fewer heath care jobs than their respective counties within a 15-minute drive. Those communities closer to the relatively dense urban centers of Fresno and Bakersfield, including Greenfield and West Fresno, enjoy greater access within 15 minutes than the regional mean. Within 45 minutes, all communities converge close to their county average levels of accessibility, as expected. Transit accessibility to health care is virtually non-existent, aside from West Fresno which enjoys some transit access via Fresno Area Express, the transit operator in the City of Fresno. Transit service in the other DUCs is available through various operators, but is generally very infrequent.

Different patterns are also evident for DUCs located relatively close to one another. Lanare and Riverdale, for example, both have low access within a 15 minute buffer but Lanare has very high automobile insufficiency while Riverdale has lower automobile insufficiency than Fresno County as a whole. We might expect residents of Lanare to acquire automobiles in greater numbers to offset their relatively poor accessibility, but this does not appear to be possible given their income demographics. In order to access health care, residents of the DUCs located further from Fresno and Bakersfield have to endure substantial travel, suggesting geographic areas for improved transit service. This analysis does not indicate whether DUC residents are undertaking these trips, however. The next section addresses travel as predicted by the model to determine the degree to which the accessibility results described here extend to commute travel.

\subsection{Commute patterns}

A major benefit of activity-based models is that properties of single trips and tours can be associated with household and individual demographics. In a four-step modeling framework, the link between trips and trip-maker demographics is severed when moving from trip generation to trip distribution; trip productions and attractions are modeled separately and destination choice is not explicitly considered in a typical four-step model. For this reason, four step-based performance metrics are generally calculated at the TAZ-level. Average properties of trips are at most disaggregated by trip purpose and associated with the demographics of a TAZ and tabulated. TAZs are not typically analyzed in isolation or for subgroups. These types of indicators can be useful, and are necessary when using aggregate models, but rely upon associating an average value with all TAZ residents that may or may not reflect individual-level travel behavior.

Table 5 reports results for modeled commute trips by DUC and other relevant geographic and demographic aggregations. These aggregations differ from those typically undertaken because 
they focus on specific communities rather than a single definition that is applied over an entire region. For example, one comparison group is all households in poverty compared to households not in poverty. Such a comparison would not be possible with an aggregate travel demand model.

The results show clear evidence of disparity in commute properties. Commute time, cost, and distance exceed county averages for Lanare, Riverdale, and Laton in Fresno County, and Weedpatch and Arvin in Kern County. Comparing DUC performance to the entire region, Lanare, Riverdale, Laton, and Arvin all underperform the regional average owing to their distance from regional job centers. For the same reasons, transit service is generally not provided, and the non-SOV commute mode share is similar to, or lower than, the county values in almost all cases.

The proportion of income spent on commuting (calculated using twice the one-way travel cost multiplied by 260) is also shown in Table 5. In the DUCs, households are allocating substantial portions of their income to travel costs. The Center for Neighborhood Technology argues that $15 \%$ of income allocated annually to transportation costs is affordable (23). The Fresno County DUCs in particular are allocating much higher proportions of their income to commuting than those in Kern. The latter DUCs are relatively closer to the jobs center of Bakersfield, while the former are more remote. Each of the DUCs, except for Greenfield, is allocating a higher proportion of their incomes to commuting than the county average. To some degree, these high costs reflect the tradeoff between housing and transportation costs, since housing is relatively less expensive in the SJV than other population centers in California, generating longer inter-regional commute patterns.

The "communities of concern" (defined as all TAZs containing $>70 \%$ people of color) aggregation does not appear to perform well as an indicator of disadvantage. The results for this definition closely match the regional average, rather than any individual DUCs. Disaggregating by poverty status, on the other hand, reveals strong differences on mode share and proportion of income spent on commuting.

The results shown in Table 5 show that disaggregation provides a powerful tool for analyzing regional equity and suggest potentially fruitful locations for transit or economic development interventions. Further, they should give pause to regional decision makers and planners developing long range plans. For example, while devoting public funds to the development of greenfield sites may be attractive as a generator of new revenue, public agencies are also obliged by federal and state civil rights laws, including Title VI of the Civil Rights Act, not to distribute funds in a discriminatory manner. Special attention must be paid to these disadvantaged areas, especially when weighing tradeoffs in investments.

\subsection{Transport by non-motorized modes}

Successful SB 375 implementation, and the implementation of smart growth policies more broadly, relies in part upon creating favorable environments for and infrastructure that supports the use of non-motorized modes. Modeled per capita time spent walking or bicycling for all trips in 2008 is summarized in Table 6 and varies substantially by DUC. Both poverty and proximity to relatively denser areas lead to increased active travel. Figure 2 illustrates the "poverty effect," showing that per capita time using non-motorized modes in a TAZ tends to decrease as the average income in the TAZ increases. 
On the other hand, Figure 2 also shows that there are many low-income TAZs that have low rates of walking and bicycling. The DUCs summarized in Table 6 also reflect these two extremes. Lanare and West Fresno exceed the Fresno County average non-motorized travel time, while Riverdale and Laton are far below the regional average. West Fresno is located close to the urban areas of Fresno and enjoys better transit access, which can affect walkability and bikeability, while Lanare is not. Lanare is poorer than both Riverdale and Laton, with a higher poverty rate and lower per capita household income (Table 2), which is likely to account for its increased travel by non-motorized modes.

Those DUCs with the lowest per capita non-motorized travel time may benefit from smart growth-type land use policies and economic development efforts, but their currently low levels of transport-related physical activity should not mean that they are not considered for such investment. Without reinvesting in these existing rural communities, SB 375 implementation runs the risk of further disadvantaging these areas.

\subsection{Geographic thresholds}

Table 5 showed that the aggregation defined using a geographic threshold for TAZs containing above $70 \%$ people of color resulted in performance measures that more closely matched the regional mean than the performance characteristics of any individual community. This finding raises a question about the suitability of the geographic threshold approach in general: when can it be relied upon to provide an accurate reflection of conditions in the communities it purports to define?

To answer this question, Figure 3 shows the results of a sensitivity analysis conducted on average commute cost, time, and distance. Each point along the $\mathrm{x}$-axis represents a particular grouping of TAZs; specifically, those TAZs that exceed that concentration of people of color. Performance was calculated at five percentage point increments ranging from 0 to 100 . The definition of aggregation becomes increasingly strict moving from left to right, so that fewer TAZs are included at each increment. At 5\% on the x-axis, all TAZs are included that exceed 5\% people of color. At $95 \%$ on the x-axis, all TAZs are included that exceed $95 \%$ people of color. The $y$-axis plots a normalized commute measure with the lowest category on the $\mathrm{x}$-axis forming the denominator. The results show that the variation in commute performance by differing community definition is low. As the proportion of people of color increases, commute times, cost, and distance generally decrease, but this is not strictly true and the magnitude of change is small. In effect, the same regional average behavior is being captured at any threshold definition because of the ways that individual populations within aggregations mix. This analysis suggests that highlighting disparities through comparing individual communities (e.g. using Tables 4-6) provides more meaningful information than using demographic thresholds.

\subsection{CONCLUSION}

The analyses presented above offer evidence that moving rural communities from the margins to the center of regional transportation and smart growth planning will yield benefits both for rural residents and for their broader regions in terms of physical health, environmental quality, and economic vitality. Recent work suggests that even small shifts in mode share from auto to non-motorized travel and transit will result in significant health benefits due to increased physical activity $(24,25)$. Capitalizing on the potential to encourage the use of non-auto modes in rural areas is likely to require financial and institutional investments in creative transportation 
approaches that can support efficient mode choices (e.g., casual carpooling, carsharing) as well as changes in the built environment (e.g., installing sidewalks and bike lanes).

While the methods presented here can identify existing inequities and suggest fruitful planning interventions, they do not provide definitive answers about how MPOs ought to direct policy and planning to reduce disparities over time. Key questions facing both MPOs and community advocates as they confront these social equity analyses include: What are the strategic intervention points in the policy and planning process that can leverage the greatest effect? How can these tools help prioritize the transportation investments and land use policies to best reduce regional inequities? Answers can be informed by the best available science and data, including those presented here. However, decisions about the goals, benchmarks, actions, and investments are not merely technical: they must arise through a civic process bringing together elected officials, planners, rural advocates and residents. The development of social equity planning tools can provide a forum for constructive and collaborative partnerships between these diverse actors (26). Such partnerships can in turn reduce the contentiousness of smart growth policy and planning and increase the legitimacy and buy-in from a broad coalition of interests to support the sustained implementation of any given plan over time.

As these partnerships based on a shared set of data and analyses move forward, the social equity tools presented here can be used at several key points in the planning process. These include baseline studies of the health and well-being of disadvantaged communities and to identify communities of concern or those places that require special consideration to prevent overburdening with additional environmental hazards (27). Finally, MPOs can adapt the tools to help inform their scenario development and assessment processes, drawing on the range of spatially explicit social equity indicators as performance metrics.

Building on the success of the smart growth framework in encouraging a renaissance in the country's urban cores, a new rural smart growth approach can support the development of prosperous, healthy, sustainable and equitable rural communities embedded in and contributing to sustainable regions. Rural communities must be engaged in the search for solutions for California and its regions to meet their GHG/VMT reduction goals.

\section{ACKNOWLEDGEMENTS}

The authors acknowledge funding from Pew Charitable Trusts, the University of California Transportation Center, and Resources Legacy Fund. The Center for Regional Change provided organizational support, and project partners including Chris Benner, Teri Greenfield, and Catherine Garoupa White provided valuable feedback.

\section{REFERENCES}

1. Handy, S. Smart growth and the transportation-land use connection: What does the research tell us? International Regional Science Review, Vol. 28, No. 2, 2005, pp. 146167.

2. Benfield, F. K., J. Terris and N. Vorsanger Solving sprawl: Models of smart growth in communities across America. 2001.

3. Martin, P. L. and J. E. Taylor. Poverty amid prosperity: Farm employment, immigration, and poverty in California. American journal of agricultural economics, Vol. 80, No. 5, 1998, pp. 1008-1014. 
4. Huang, G. and J. K. London. Cumulative environmental vulnerability and environmental justice in California's San Joaquin Valley. International Journal of Environmental Research and Public Health, Vol. 9, No. 5, 2012, pp. 1593-1608.

5. Rubin, V., A. Chandler, E. Bernabei and R. Lizardo. Unincorporated Communities in the San Joaquin Valley: New Responses to Poverty, Inequity, and a System of Unresponsive Governance. California Rural Legal Assistance and PolicyLink, Fresno, CA, 2007.

6. Anderson, M. W. Mapped out of local democracy. Stanford Law Review, Vol. 62, 2009, pp. 931-1003.

7. Kramer, D. United Voices: An Open Proposal for Smart and Fair Growth in the Central Valley. Ecology LQ, Vol. 39, 2012, pp. 193-193.

8. Rails-to-Trails Conservancy. Active Transportation Beyond Urban Centers: Walking and Bicycling in Small Towns and Rural America. Washington, DC, 2012.

9. Karner, A. and D. Niemeier. Review of environmental justice and equity analysis methods in the San Joaquin Valley. http://goo.gl/qjdDz.

10. Council of Fresno County Governments. Fresno Council of Governments Environmental Justice Plan. Fresno, CA, 2009.

11. Karner, A. and D. Niemeier. Civil rights guidance and equity analysis methods for regional transportation plans: a critical review of literature and practice. Journal of Transport Geography, Vol. 33, 2013, pp. 126-134.

12. Karner, A. and D. Niemeier. Civil Rights Guidance and Equity Analysis Methods for Regional Transportation Plans: A Critical Review of Literature and Practice. Working paper, 2013.

13. ULTRANS and HBA Specto Incorporated. SJVITM - San Joaquin Valley Interregional Travel Model. Model Development: Model Overview. Final Draft System Documentation. Davis, California, 2012.

14. US Census Bureau. Poverty Thresholds 2008. http://www.census.gov/hhes/www/poverty/data/threshld/thresh08.html.

15. Maizlish, N., J. Woodcock, S. Co, B. Ostro, A. Fanai and D. Fairley. Health Co-Benefits and Transportation-Related Reductions in Greenhouse Gas Emissions in the Bay Area: Technical Report. California Department of Public Health, 2012.

16. The California Endowment. Building Healthy Communities: Our Vision. http://www.calendow.org/healthycommunities/index.html.

17. Geurs, K. T. and B. van Wee. Accessibility evaluation of land-use and transport strategies: review and research directions. Journal of Transport Geography, Vol. 12, No. 2, 2004, pp. 127-140.

18. Kwan, M.-P. Space-Time and Integral Measures of Individual Accessibility: A Comparative Analysis Using a Point-based Framework. Geographical Analysis, Vol. 30, No. 3, 1998, pp. 191-216.

19. Handy, S. L. and D. A. Niemeier. Measuring accessibility: an exploration of issues and alternatives. Environment and Planning A, Vol. 29, No. 7, 1997, pp. 1175-1194.

20. Golub, A., G. Robinson and B. Nee. Making accessibility analyses accessible: A tool to facilitate the public review of the effects of regional transportation plans on accessibility. Journal of Transport and Land Use, Vol. 6, No. 3, In press, pp.

21. Chan, L., L. G. Hart and D. C. Goodman. Geographic Access to Health Care for Rural Medicare Beneficiaries. The Journal of Rural Health, Vol. 22, No. 2, 2006, pp. 140-146. 
22. Arcury, T. A., J. S. Preisser, W. M. Gesler and J. M. Powers. Access to Transportation and Health Care Utilization in a Rural Region. The Journal of Rural Health, Vol. 21, No. 1, 2005, pp. 31-38.

23. Center for Neighborhood Technology. H+T Index (Methodology Report). http://htaindex.cnt.org/downloads/HTMethods.2011.pdf.

24. Maizlish, N., J. Woodcock, S. Co, B. Ostro, A. Fanai and D. Fairley. Health Cobenefits and Transportation-Related Reductions in Greenhouse Gas Emissions in the San Francisco Bay Area. American Journal of Public Health, Vol. 103, No. 4, 2013, pp. 703709.

25. Woodcock, J., P. Edwards, C. Tonne, B. G. Armstrong, O. Ashiru, D. Banister, S. Beevers, Z. Chalabi, Z. Chowdhury, A. Cohen, O. H. Franco, A. Haines, R. Hickman, G. Lindsay, I. Mittal, D. Mohan, G. Tiwari, A. Woodward and I. Roberts. Public health benefits of strategies to reduce greenhouse-gas emissions: urban land transport. The Lancet, Vol. 374, No. 9705, 2009, pp. 1930-1943.

26. Benner, C. and M. Pastor. Moving on up? Regions, megaregions, and the changing geography of social equity organizing. Urban Affairs Review, Vol. 47, No. 3, 2011, pp. 315-348.

27. Clinton, W. J. Federal Actions to Address Environmental Justice in Minority Populations and Low-Income Populations. Federal Register, Vol. 59, No. 32, 1994, pp. 7629-7633. 


\section{LIST OF TABLES AND FIGURES}

TABLE 1 Relationship Between DUCs and TAZs.

TABLE 2 Key Demographics in Study Communities, Corresponding Counties, and Statewide.

TABLE 3 Mean Modeled Cumulative Opportunities Accessibility by Time Band and Mode, all SJV TAZs, 2008.

TABLE 4 Modeled Mean Cumulative Opportunities Accessibility (Automobile, Transit, and Composite) to Healthcare Jobs Within 15, 30, and 45 minutes of Study DUCs and Counties, AM peak period, 2008.

TABLE 5 Mean Commute Statistics by DUC and Other Aggregated Populations.

TABLE 6 Active Travel in DUCs and Other Aggregate Geographies, All Trips, 2008.

FIGURE 1 Location of eight study DUCs (bright green) within the eight county San Joaquin Valley region (Fresno County and Kern County in blue). Location within California, major cities of Fresno and Bakersfield, and all Census designated places (dark grey) shown.

FIGURE 2 Scatterplot of TAZ-level per capita time spent traveling using non-motorized modes and average income in the TAZ.

FIGURE 3 Normalized commute properties and the effect of changing the threshold definition for geographic aggregations. 
Karner and London

TABLE 1 Relationship Between DUCs and TAZs.

\begin{tabular}{|l|c|c|c|}
\cline { 2 - 4 } \multicolumn{1}{c|}{} & Count of included TAZs & TAZ population (2008) & Actual population (2010) \\
\hline Lanare CDP & 1 & 1,124 & 589 \\
\hline Riverdale CDP & 1 & 1,947 & 3,153 \\
\hline Laton CDP & 1 & 1,122 & 1,824 \\
\hline West Fresno & 82 & 67,064 & 39,076 \\
\hline Arvin city & 8 & 17,349 & 19,304 \\
\hline Lamont CDP & 7 & 11,591 & 15,120 \\
\hline Greenfield CDP & 8 & 3,920 & 3,991 \\
\hline Weedpatch CDP & 2 & 2,688 & 2,658 \\
\hline
\end{tabular}


TABLE 2 Key Demographics in Study Communities, Corresponding Counties, and Statewide.

\begin{tabular}{|c|c|c|c|c|c|c|}
\hline & Population $^{a}$ & $\begin{array}{l}\text { Poverty } \\
(\%)^{b}\end{array}$ & $\begin{array}{c}\text { Per capita } \\
\text { HH income } \\
(2011 \$)^{b}\end{array}$ & $\begin{array}{l}\text { People of } \\
\text { color } \\
(\%)^{a}\end{array}$ & $\begin{array}{c}\text { Non-SOV } \\
\text { commute } \\
\text { mode } \\
\text { share }(\%)^{b}\end{array}$ & $\begin{array}{c}\text { Linguistic } \\
\text { isolation } \\
(\%)^{b, c}\end{array}$ \\
\hline Lanare CDP & 589 & 36.5 & 10,581 & 98.5 & - & 43.4 \\
\hline Riverdale CDP & 3,153 & 30.3 & 14,542 & 70.8 & - & 35.2 \\
\hline Laton CDP & 1,824 & 4.7 & 20,941 & 77.6 & - & 14.8 \\
\hline West Fresno $^{d}$ & 39,076 & 41.2 & 11,860 & 89.0 & 37.5 & 29.1 \\
\hline Fresno county & 930,450 & 23.4 & 20,638 & 67.3 & 23.3 & 19.2 \\
\hline Arvin city & 19,304 & 34.9 & 9,241 & 94.8 & 37.0 & 47.6 \\
\hline Lamont CDP & 15,120 & 28.8 & 10,332 & 95.4 & 40.6 & 46.4 \\
\hline Greenfield CDP & 3,991 & 9.1 & 24,126 & 61.9 & - & 22.6 \\
\hline Weedpatch CDP & 2,658 & 36.4 & 8,620 & 94.4 & - & 57.6 \\
\hline Kern county & 839,631 & 21.4 & 20,167 & 61.4 & 24.4 & 17.9 \\
\hline Statewide & $36,995,499$ & 14.4 & 29,634 & 59.9 & 27.0 & 19.7 \\
\hline
\end{tabular}

Missing data indicate a margin of error greater than or equal to $50 \%$ of the estimate.

aSource: Census 2010, Summary File 1.

${ }^{b}$ Source: American Community Survey, 2007 - 2011 five year estimates.

cDefined as those speaking English less than "very well."

${ }^{d}$ Defined as Zip Code Tabulation Area 93706; all data from the American Community Survey, 2007 2011 five year estimates. 
TABLE 3 Mean Modeled Cumulative Opportunities Accessibility by Time Band and Mode, all SJV TAZs, 2008. ${ }^{a}$

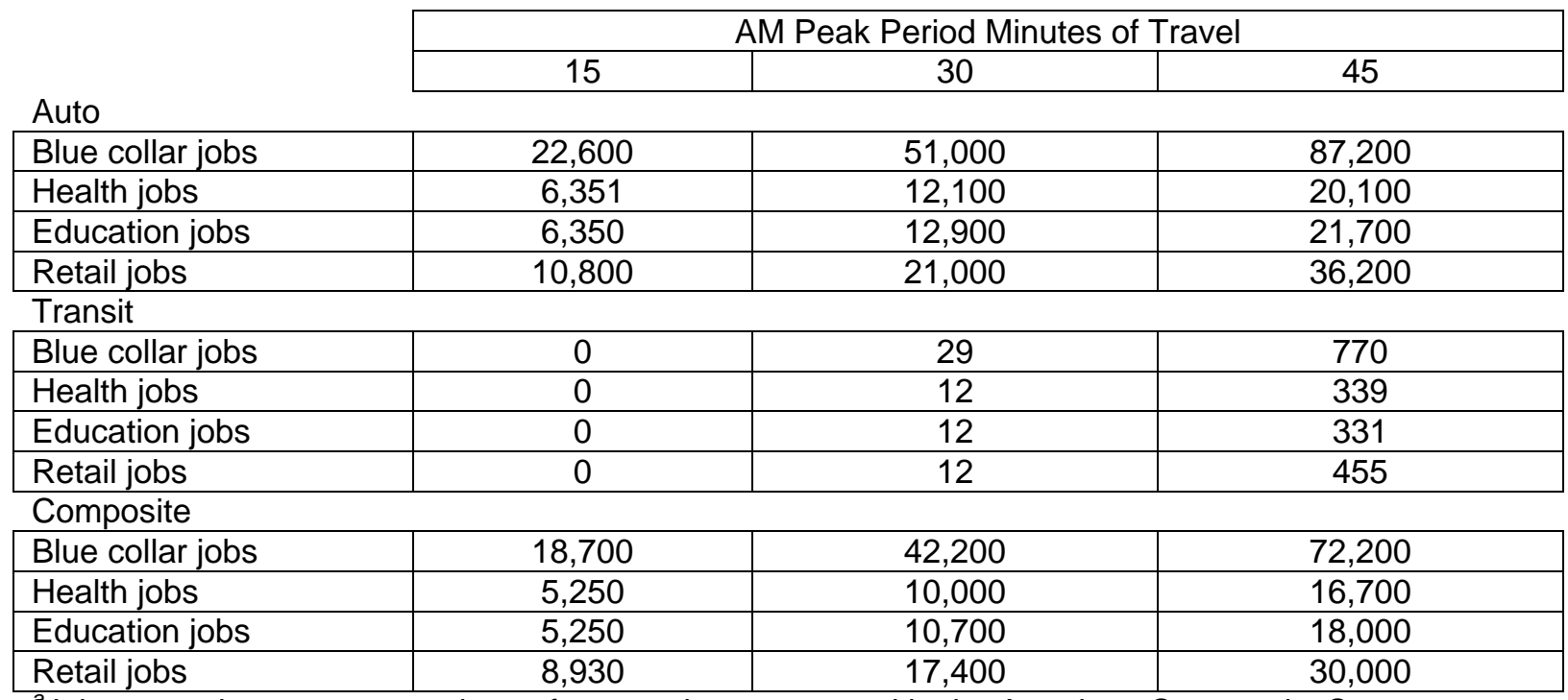

${ }^{2}$ Job categories are aggregations of occupation types used in the American Community Survey. 
TABLE 4 Modeled Mean Cumulative Opportunities Accessibility (Automobile, Transit, and Composite) to Healthcare Jobs Within 15, 30, and 45 minutes of Study DUCs and Counties, AM peak period, 2008.

\begin{tabular}{|c|c|c|c|c|c|}
\hline & \multirow{2}{*}{$\begin{array}{l}\text { Modeled proportion } \\
\text { of automobile } \\
\text { insufficient } \\
\text { households }^{a}\end{array}$} & & \multicolumn{3}{|c|}{ Minutes } \\
\hline & & & 15 & 30 & 45 \\
\hline \multirow{3}{*}{ Lanare CDP } & \multirow{3}{*}{$25 \%$} & Auto & 43 & 1,590 & 20,500 \\
\hline & & Transit & 0 & 0 & 0 \\
\hline & & Composite & 32 & 1,189 & 15,334 \\
\hline \multirow{3}{*}{ Riverdale CDP } & \multirow{3}{*}{$14 \%$} & Auto & 154 & 9,920 & 28,000 \\
\hline & & Transit & 0 & 0 & 0 \\
\hline & & Composite & 133 & 8,582 & 24,223 \\
\hline \multirow{3}{*}{ Laton CDP } & \multirow{3}{*}{$18 \%$} & Auto & 73 & 6,660 & 28,200 \\
\hline & & Transit & 0 & 0 & 0 \\
\hline & & Composite & 60 & 5,434 & 23,008 \\
\hline \multirow{3}{*}{ West Fresno } & \multirow{3}{*}{$23 \%$} & Auto & 14,451 & 21,800 & 30,600 \\
\hline & & Transit & 0 & 20 & 550 \\
\hline & & Composite & 11,176 & 16,865 & 23,791 \\
\hline \multirow{3}{*}{ Fresno county } & \multirow{3}{*}{$16 \%$} & Auto & 11,600 & 18,800 & 26,000 \\
\hline & & Transit & 0 & 10 & 480 \\
\hline & & Composite & 9,718 & 15,752 & 21,861 \\
\hline \multirow{3}{*}{ Arvin city } & \multirow{3}{*}{$20 \%$} & Auto & 236 & 9,465 & 11,300 \\
\hline & & Transit & 0 & 0 & 0 \\
\hline & & Composite & 190 & 7,602 & 9,075 \\
\hline \multirow{3}{*}{ Lamont CDP } & \multirow{3}{*}{$18 \%$} & Auto & 1,800 & 10,915 & 12,100 \\
\hline & & Transit & 0 & 0 & 0 \\
\hline & & Composite & 1,474 & 8,939 & 9,910 \\
\hline \multirow{3}{*}{ Greenfield CDP } & \multirow{3}{*}{$8 \%$} & Auto & 9,110 & 11,000 & 12,500 \\
\hline & & Transit & 0 & 0 & 2 \\
\hline & & Composite & 8,416 & 10,162 & 11,548 \\
\hline \multirow{3}{*}{ Weedpatch CDP } & \multirow{3}{*}{$22 \%$} & Auto & 1,120 & 11,000 & 11,800 \\
\hline & & Transit & 0 & 0 & 0 \\
\hline & & Composite & 874 & 8,580 & 9,204 \\
\hline \multirow{3}{*}{ Kern county } & \multirow{3}{*}{$19 \%$} & Auto & 5,400 & 8,380 & 11,000 \\
\hline & & Transit & 0 & 0 & 45 \\
\hline & & Composite & 4,397 & 6,824 & 8,966 \\
\hline
\end{tabular}

${ }^{a}$ Households with number of vehicles equal to or less than the number of licensed drivers. 
TABLE 5 Mean Commute Statistics by DUC and Other Aggregated Populations.

\begin{tabular}{|c|c|c|c|c|c|}
\hline & \multicolumn{3}{|c|}{ One-way trip properties } & \multirow{2}{*}{$\begin{array}{l}\text { Non-SOV } \\
\text { mode } \\
\text { share (\%) }\end{array}$} & \multirow{2}{*}{$\begin{array}{l}\text { Proportion of } \\
\text { household } \\
\text { income spent on } \\
\text { commuting }\end{array}$} \\
\hline & $\begin{array}{l}\text { Time } \\
(\min )\end{array}$ & $\begin{array}{c}\text { Cost } \\
(2008 \$)\end{array}$ & $\begin{array}{l}\text { Distance } \\
\quad(\mathrm{mi})\end{array}$ & & \\
\hline Lanare CDP & 40.00 & 10.77 & 29.00 & 20 & 37.6 \\
\hline Riverdale CDP & 30.70 & 9.25 & 24.30 & 16 & 24.2 \\
\hline Laton CDP & 35.80 & 8.95 & 24.40 & 20 & 24.2 \\
\hline West Fresno & 16.26 & 3.61 & 9.90 & 24 & 12.0 \\
\hline Fresno county & 16.76 & 3.89 & 10.36 & 19 & 10.6 \\
\hline Arvin city & 22.20 & 6.48 & 16.96 & 19 & 18.0 \\
\hline Lamont CDP & 15.93 & 4.25 & 11.24 & 20 & 13.4 \\
\hline Greenfield CDP & 13.70 & 3.66 & 9.50 & 14 & 9.60 \\
\hline Weedpatch CDP & 17.80 & 4.77 & 12.60 & 19 & 13.4 \\
\hline Kern county & 16.52 & 4.12 & 10.89 & 19 & 11.4 \\
\hline Regionwide & 19.70 & 4.97 & 13.10 & 19 & 12.6 \\
\hline $\begin{array}{l}\text { "Communities of concern" } \\
\text { (TAZs with }>70 \% \text { people of } \\
\text { color) }\end{array}$ & 19.27 & 4.87 & 12.97 & 21 & 14.2 \\
\hline Households in poverty & 18.58 & 3.68 & 10.84 & 40 & 25.8 \\
\hline Households not in poverty & 19.80 & 5.09 & 13.29 & 17 & 11.2 \\
\hline
\end{tabular}


TABLE 6 Active Travel in DUCs and Other Aggregate Geographies, All Trips, 2008.

\begin{tabular}{|l|c|}
\cline { 2 - 2 } \multicolumn{1}{c|}{} & Per capita active travel time (min) \\
\hline Lanare CDP & 14.7 \\
\hline Riverdale CDP & 6.76 \\
\hline Laton CDP & 6.14 \\
\hline West Fresno & 14.1 \\
\hline Fresno county & 11.3 \\
\hline Arvin city & 9.63 \\
\hline Lamont CDP & 12.6 \\
\hline Greenfield CDP & 7.61 \\
\hline Weedpatch CDP & 10.9 \\
\hline Kern county & 12.2 \\
\hline Regionwide & 11.3 \\
\hline "Communities of concern" & 12.5 \\
\hline Households in poverty & 20.2 \\
\hline Households not in poverty & 9.00 \\
\hline
\end{tabular}




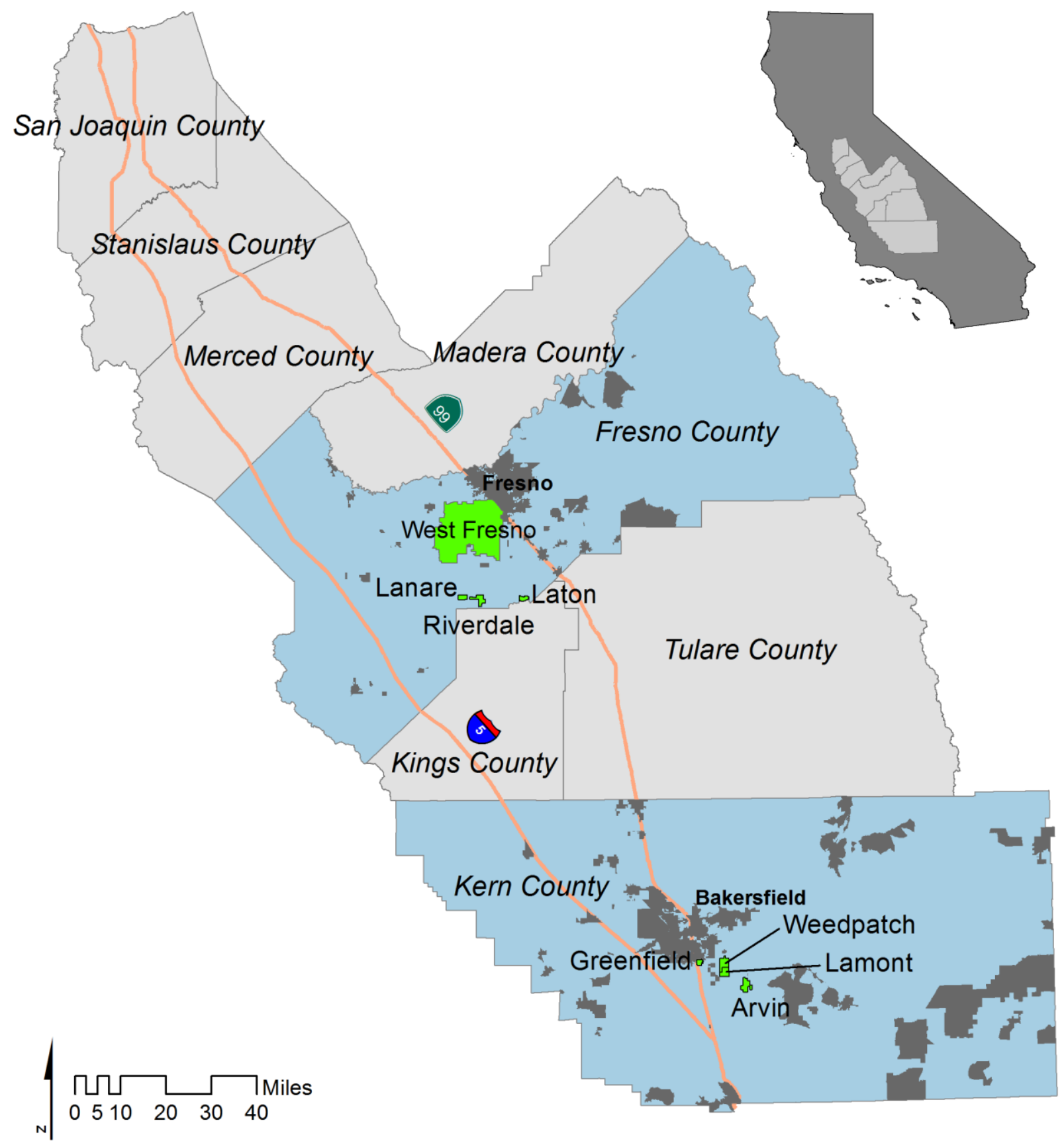

FIGURE 1 Location of eight study DUCs (bright green) within the eight county San Joaquin Valley region (Fresno County and Kern County in blue). Location within California, major cities of Fresno and Bakersfield, and all Census designated places (dark grey) shown. 


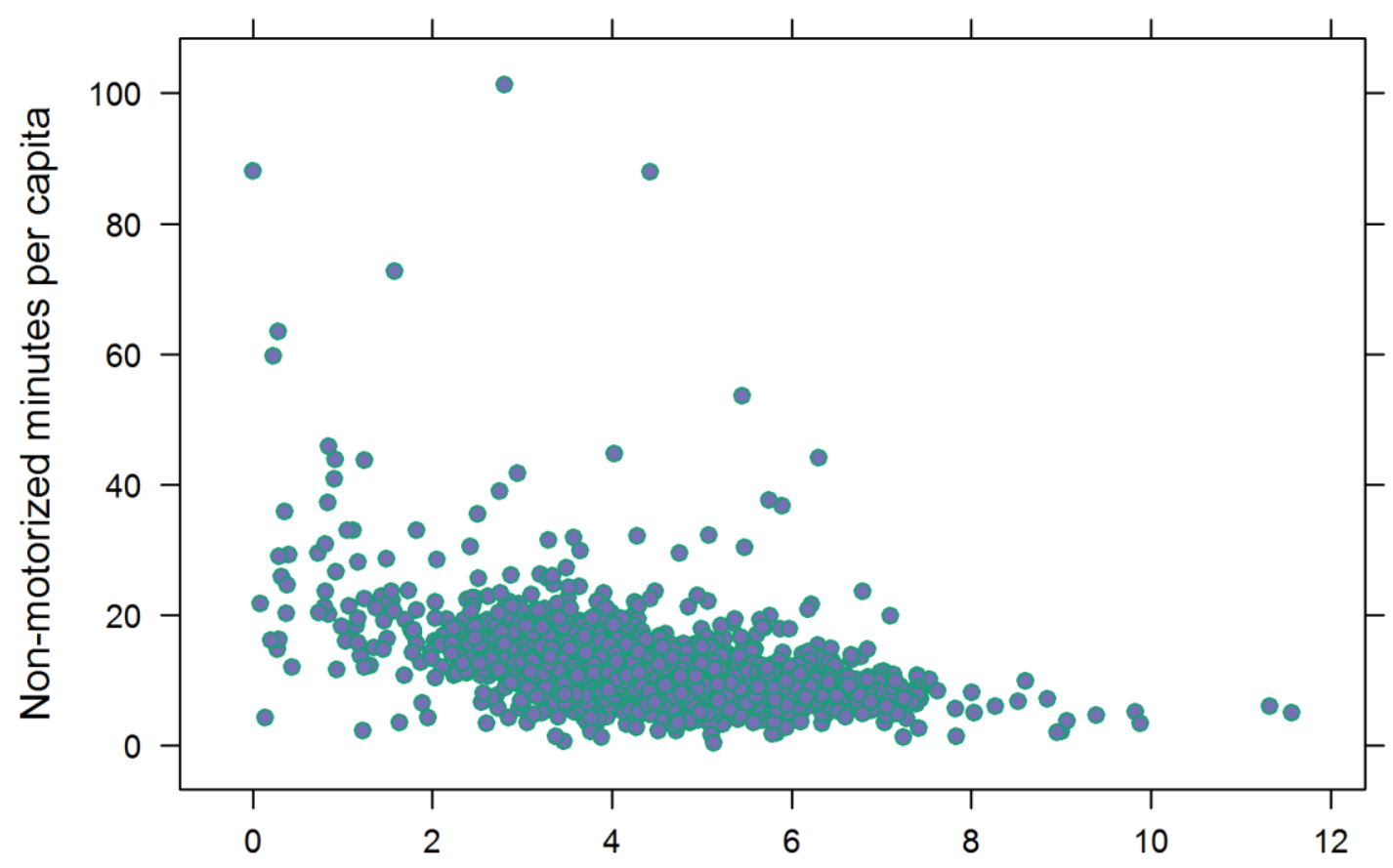

TAZ-level average income, ten thousand year 2000 dollars

FIGURE 2 Scatterplot of TAZ-level per capita time spent traveling using non-motorized modes and average income in the TAZ. 


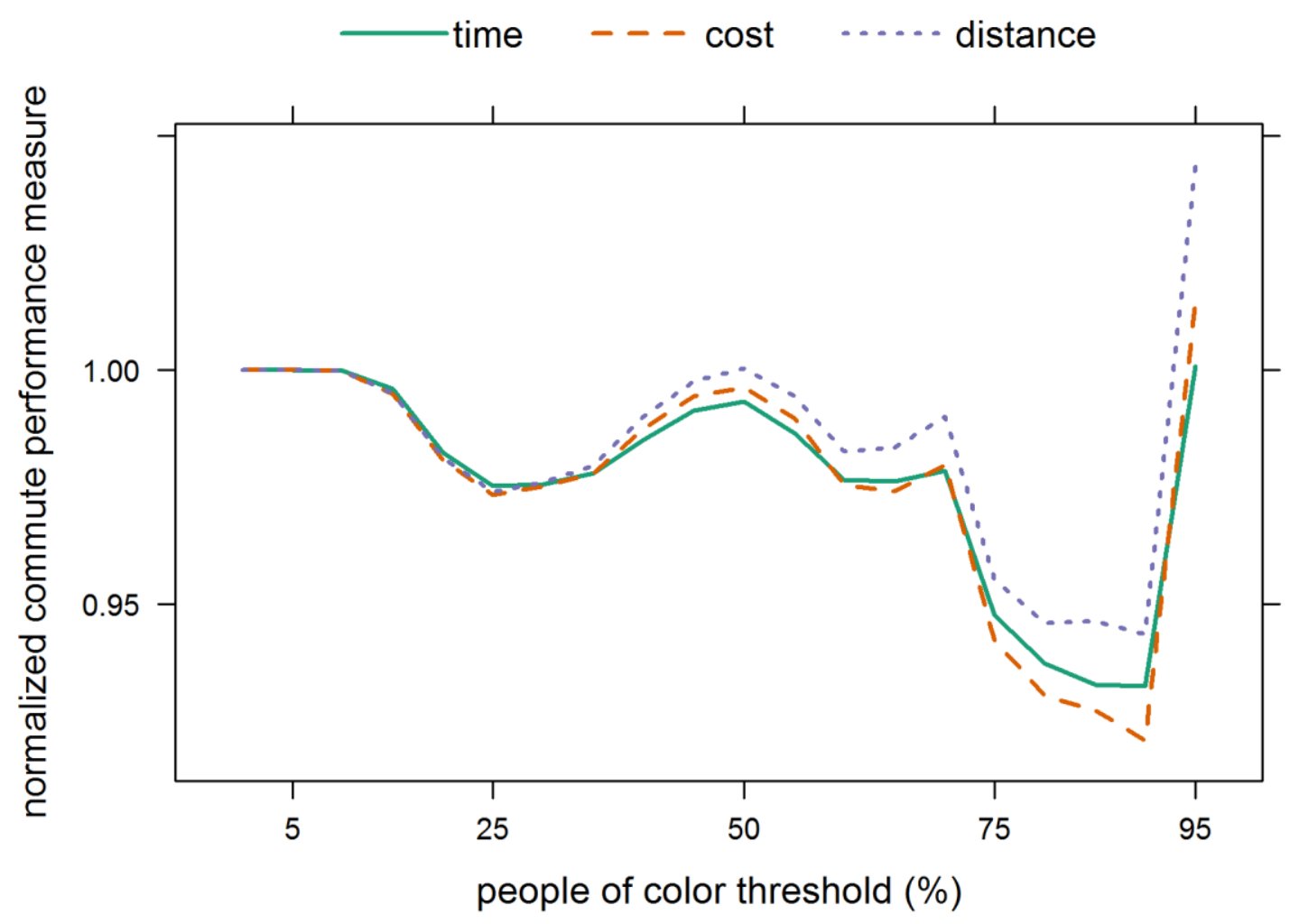

FIGURE 3 Normalized commute properties and the effect of changing the threshold definition for geographic aggregations. 